\title{
LA INCORPORACIÓN DE EJES \\ TRANSVERSALES EN LA EDUCACIÓN SUPERIOR: EL MARCO INSTITUCIONAL Y ELACOMPAÑAMIENTO COMO CONDICIONES PARA EL ÉXITO
}

\section{Claudia Charpentier Esquivel ${ }^{1}$ Lupita Jiménez Reyes Virginia Sánchez Molina}

\section{Resumen}

La Universidad Nacional acordó incluir cinco ejes transversales institucionales en los planes de estudio. Para tener éxito, organizó un proceso que consideró dos componentes fundamentales: el marco institucional y el acompañamiento a docentes y unidades académicas, y así ayudar a reducir las barreras que podrían interferir en la incorporación de género, desarrollo sostenible, ambiente y cultura ambiental, equidad y diversidad cultural.

En este trabajo se presentan el marco institucional y los aspectos que se atendieron en el acompañamiento y las actualizaciones que se brindaron al personal docente y administrativoacadémico.

Palabras claves: transversalidad, educación, plan de estudio.

\section{Abstract}

The National University decided to include five institutional transverse axes in the curricula. In order to be successful, a process was undertaken, that considered two fundamental components: the institutional framework and joint work with professors and

1 Programa de Evaluación y Gestión de la Calidad Académica, Proyecto de Ejes Transversales Institucionales. Universidad Nacional, Heredia, Costa Rica. 
departments, as a mean of reducing barriers that could interfere in the inclusion of gender, sustainable development, environment and environmental culture, equity and cultural diversity in curricula.

In this paper are included, the institutional framework and the aspects that were considered during the joint work as well as the training provided to faculty and chairpersons during the process.

Keywords: curricula, transverse axes, education.

\section{Introducción}

$\mathrm{Al}^{1}$ eje transversal que más se ha logrado incluir en las universidades es el del ambiente. Como consecuencia, hay resultados concretos, entre ellos, están los acuerdos logrados en la Cumbre de Río en el 92 y más reciente la Declaración de Talloires (Benayas y Alba, s.f.), de la cual es signataria la Universidad Nacional. Estos acuerdos deben generar esfuerzos institucionales tal y como lo piantean Benayas y Alba (s.f.), quienes abordan este aspecto en los retos de la ambientalización universitaria o las recomendaciones para incluir la dimensión ambiental en la formación de profesionales universitarios (Romero, 1991).

En Costa Rica, durante más de diez años, la Comisión Interuniversitaria de Educación Ambiental coordina los esfuerzos para incluir el ambiente como una dimensión en los planes de estudio de las universidades (Charpentier, 2005). De ese trabajo, sobresalen las investigaciones para incluir el ambiente en los planes de formación de docentes en la Universidad Nacional y la Universidad de Costa Rica (Charpentier, 1999; Mata et al., 2002) y los indicadores para evaluar la incorporación de la dimensión ambiental en los planes de estudio (Charpentier et al., 2002).

En todos los casos, es claro que el simple hecho de incluir asignaturas como ecología o problemas ambientales en el plan de estudio no logran ambientalizarlo. Como plantean Benayas y Alba (s.f.): "entendemos por ambientalización universitaria el proceso de reconocimiento de los impactos que se provocan en la cotidianidad y de los cambios a acaecer para contrarrestarlos". Por lo tanto, en un esfuerzo como el que realiza la Universidad Nacional, es necesario tener en cuenta que las decisiones y acuerdos de las autoridades universitarias, por sí solos, tampoco lograrán incluir los ejes transversales en el quehacer universitario. 
El análisis de las condiciones que favorecen o limitan la incorporación del ambiente en los planes de estudio motivó la realización de una investigación con docentes de las cuatro universidades estatales de Costa Rica (Charpentier, 1995). Esos estudios mostraron que los cambios en la enseñanza superior, provocaban que el personal docente creyera que tiene dificultades que impiden incluir esas transformaciones en su práctica docente (Charpentier, 1995; Charpentier y Ham, 1997); esos obstáculos se llaman barreras. En el contexto académico y de acuerdo con Ham y Sewing (1988), una barrera es la creencia que tiene el o la docente que desanima o impide que cambie o amplíe su práctica profesional.

Dos ejemplos recientes de cambio de la práctica docente son la incorporación de las nuevas tecnologías (TICs) y la ambientalización de cursos en los planes de estudio (Ávila, 2001; Benayas y Alba, s.f.; Mata et al., 2003).

Este trabajo se referirá sólo al último aspecto, por ser uno de los ejes transversales en la Universidad Nacional de Costa Rica. Sin embargo, se mencionan las TICs, porque el proceso ha incluido el uso de la tecnología y porque hay esfuerzos de muchas universidades para incluir las TICs en la docencia que no han considerado las barreras que el personal docente pueda tener.

\section{Incorporación del ambiente en las universidades estatales}

Charpentier (1995) identificó las barreras que tenía el profesorado de las universidades estatales de Costa Rica, para incluir el ambiente como una dimensión en los planes de estudio y cursos. Con base en dicho estudio, se ajustaron las definiciones para su aplicación en la incorporación de los ejes transversales. En este marco, las barreras para cambiar o ampliar la práctica docente universitaria son de tres tipos: barreras actitudinales, se fundamentan en las creencias del personal docente de que otras demandas son más importantes en la distribución de su tiempo, que incluir ejes transversales; barreras conceptuales, se originan en la concepción errónea de los alcances y objetivos de la educación ambiental o de la incorporación de los ejes transversales y, por último, las barreras de control, que se originan de la percepción de docentes sobre la falta de oportunidad, habilidad, recursos -incluyendo tiempo y dinero- para incorporar los ejes transversales en su quehacer.

Los resultados de Charpentier (1995) fueron considerados por la Comisión Interuniversitaria de Educación Ambiental de Costa Rica para elaborar la primera investigación que permitió sistematizar y dar seguimiento a la 
inclusión del ambiente como una dimensión en los planes de formación de docentes de Preescolar y de Primero y Segundo Ciclo de la División de Educación Básica de la Universidad Nacional (UNA) y de la Universidad de Costa Rica (UCR) (Mata et al., 2003 y Mata et al., 2002). En ese estudio, las integrantes de la Comisión trabajaron en pares o triadas con las y los docentes seleccionados para realizar la experiencia; de esa forma, se atendieron las necesidades de cada una de esas personas.

Charpentier (2005) analizó el trabajo de esos grupos y determinó que el apoyo brindado ayudó a superar las barreras de control y algunas barreras actitudinales, porque el personal docente participante tenía claridad en los conceptos relativos a la educación ambiental y contaba con una actitud positiva hacia la incorporación del ambiente. Esta experiencia realizada en la UNA y en la UCR sirvió como referente para propuestas de incorporación de ejes transversales en todas las universidades estatales costarricenses.

\section{Inclusión de los ejes transversales en la UNA}

\section{El marco institucional}

La Universidad Nacional, desde sus inicios, ha planteado la importancia de fomentar el desarrollo humano integral, la necesidad de brindar una formación humanista que considere e incorpore una serie de valores que han sido definidos desde la misión, los principios y fines.

La Universidad Nacional (2005) se plantea desde la Misión:

El quehacer de la Universidad Nacional consiste en la formación de profesionales de excelencia en diversos campos de conocimiento y disciplinas cientificas y artísticas, con principios y conocimientos humanistas, con conciencia ambiental y respeto por la vida, críticos, propositivos y capaces de generar aportes sustantivos a la sociedad (p. 36).

Asimismo, señala desde la Visión compartida:

La Universidad Nacional (2005), se constituye en un importante centro académico de América Latina en el abordaje de asuntos estratégicos para el desarrollo humano sostenible y contribuye con sus aportes al desarrollo del conocimiento y a mejorar la calidad de vida en el ámbito 
nacional e internacional. La Universidad Nacional forma profesionales de excelencia, con una visión holistica, propositivos, innovadores, capaces de contribuir significativamente a un desarrollo humano equitativo y sostenible. La oferta académica institucional es actualizada, flexible, rigurosa y pertinente. La docencia utiliza un modelo pedagógico innovador e incorpora el uso de las nuevas tecnologías para responder a los avances del conocimiento (p. 37).

En este sentido, la UNA se propone:

- $\quad$ Entre los principios

- La Responsabilidad ambiental: las acciones institucionales son consecuentes con la responsabilidad y el compromiso por heredar un mundo habitable a las futuras generaciones.

- El Humanismo: el bienestar, la realización y la convivencia humana constituyen el propósito de todos los esfuerzos del desarrollo institucional (Universidad Nacional, 2005, p. 39).

- $\quad$ Entre los Valores

- Equidad: es la condición de trato equitativo en oportunidades y derechos entre hombres y mujeres, jóvenes y adultos, de forma que se desarrollen plenamente sin discriminación por razones de sexo, clase social, religión o etnia.

- Compromiso con el ambiente: es el esfuerzo por desarrollar prácticas y una actitud de respeto por las distintas formas de vida y el ambiente, así como el compromiso de heredar a las futuras generaciones un planeta más habitable (Universidad $\mathrm{Na}$ cional, 2005, p. 42).

- Desde la estrategia institucional

- El modelo pedagógico se orienta a formar a los estudiantes mediante procesos comunicativos rigurosos, fundamentados en el respeto mutuo y la búsqueda de la verdad, con experiencias vivenciales que permitan el aprendizaje en cuanto a hacer, ser, aprender y convivir, e incorpora la tecnología como recurso pedagógico (Universidad Nacional, 2005, p. 41). 
Este marco institucional propicia la incorporación de los principios y valores como rasgos del perfil del graduado, los cuales se encuentran planteados en los planes de estudio de las diversas carreras. Sin embargo, no existe la práctica de rescatarlos en el desarrollo de los diferentes cursos, puesto que los profesores, en su mayoría, se preocupan por desarrollar los contenidos y lograr el aprendizaje de los conocimientos; dejan de lado el aporte de cada uno de los cursos y actividades curriculares al perfil del graduado en cuanto al desarrollo de valores, actitudes y aptitudes. No debe olvidarse que estos aspectos son de fundamental importancia, dada la crisis de valores de nuestra sociedad.

Es mediante la aprobación de la Política Ambiental, por el Consejo Universitario después de un proceso participativo de discusión, que la Universidad Nacional, como Institución de Educación Superior de excelencia académica, de acuerdo con sus valores, misión, principios, fines y funciones establecidos en el Estatuto Orgánico y de los esfuerzos que viene realizando, asume un compromiso en relación con su responsabilidad ambiental presente y futura, con el desarrollo integral, autónomo, sostenible y equilibrado de la sociedad. Por eso, se propone desarrollar su quehacer según una serie de compromisos en relación con la formación de sus estudiantes y funcionarios (Consejo Universitario, 2003b):

- formará profesionales con una clara conciencia y responsabilidad ambiental que se refleje en su desempeño profesional.

- promoverá actividades académicas que fortalezcan una cultura ambiental de excelencia.

- $\quad$ ejecutará todas las actividades académicas, administrativas y de servicios en general con base en principios que aseguren que estas sean cada vez más amigables con el ambiente.

Para cumplir con dichos compromisos, se proponen, entre otras, las siguientes estrategias:

- $\quad$ concienciar y capacitar a funcionarios y estudiantes para tener condiciones de éxito que permitan desarrollar procesos para lograr un adecuado desempeño ambiental.

- concienciar a funcionarios y estudiantes sobre su papel y responsabilidad como ciudadanos y profesionales en relación con el ambiente.

- incorporar la dimensión ambiental en los currículos de sus carreras. 
- $\quad$ incorporar la dimensión ambiental en el quehacer universitario en general: proyecto y, programas de investigación, extensión, producción y servicios.

- $\quad$ contribuir con los esfuerzos que se realizan nacionalmente por el fortalecimiento de la conciencia ambiental y la divulgación de conocimientos y tecnología que se refleje en un comportamiento ambiental adecuado.

- desarrollar incentivos y disuasivos que coadyuven en el logro de una cultura ambiental y la internalización de la dimensión ambiental en todas las acciones del quehacer universitario.

Por otra parte, es importante considerar en este ámbito el Sistema de Gestión Ambiental, SIGA-UNA, cuyo objetivo es:

Organizar y sistematizar las acciones de gestión ambiental requeridas para ejecutar la Política Ambiental de la Universidad Nacional, como actividades ordinarias inmersas en el quehacer institucional, que le permitan cumplir con su responsabilidad ambiental presente y futura.

El SIGA-UNA, en el desarrollo de las actividades para cumplir con su Programa Ambiental, permitirá a los estudiantes desarrollar actitudes, hábitos, comportamientos que inciden en su formación, puesto que se incorporan en la cotidianeidad como vivencias.

En este sentido, un estudiante que durante cinco años o más ha separado los desechos ordinarios y visualizado su manejo integral, incluyendo el reúso, la venta para reciclaje, la minimización, el rechazo a productos no amigables como el estereofón, la disposición final adecuada, ha realizado actividades específicas de manejo adecuado de desechos peligrosos, ha visto cómo se manejan las aguas residuales en las plantas de tratamiento de la universidad, ha minimizado y racionalizado el uso del agua en los baños y en los laboratorios, ha minimizado y usado racionalmente la energía eléctrica, entre otros, ha internalizado una vivencia ambiental que se reflejará en su desempeño profesional.

Con base en esta Política, sus compromisos y estrategias, el Programa de Evaluación y Gestión de la Calidad Académica propone desarrollar un proyecto que permita incorporar la dimensión ambiental en los planes de estudio. Al respecto, considerando que los individuos y los grupos actúan sobre su ambiente a partir del sistema de creencias y representaciones que 
manejan, este proyecto parte de una conceptualización amplia del ambiente como:

La totalidad en la que lo inerte y lo biótico incluido el ser humano interactúan y se condicionan y afectan mutuamente, formando sistemas dinámicos y en permanente cambio. Considera la interacción de los aspectos sociales, económicos, culturales, ecológicos, tecnológicos, éticos, de salud, bienestar y calidad de vida.

Esto lleva a la necesidad de incluif otros aspectos además del meramente ecológico, como desarrollo humano sostenible, equidad, género, diversidad, entre otros, que influyen en las relaciones del ser humano con la naturaleza y del ser humano con sus semejantes, pues cada persona ha se ser considerada en una formación humanista integral.

Este proyecto visualiza la oportunidad del proceso de rediseño curricular que debe realizar en todas sus carreras la Universidad Nacional para la reorganización del ciclo lectivo e incorporar los ejes transversales institucionales de la UNA. En este sentido, se propone incluir una directriz en las nuevas Políticas y Lineamientos Curriculares que orientarían el proceso de rediseño.

De esta manera, en las Políticas y Lineamientos Curriculares (Consejo Universitario, 2003, p. 4) se señala entre otros que:

Es interés institucional que todo plan de estudios:

- $\quad$ oriente la formación de profesionales para que estén en capacidad de interpretar y dar respuesta a los retos de las tendencias actuales de desarrollo del país y de las diferentes regiones,

- garantice en su organización y ejecución tanto la formación humanista como el desarrollo de los valores y ejes definidos institucionalmente, en concordancia con la misión de la Universidad Nacional.

En este marco institucional de principios, valores, políticas, lineamientos y estrategias, la UNA realiza su proceso de definición e incorporación de los ejes transversales institucionales. Podemos decir que contar con un marco institucional es un factor de éxito para la incorporación de los ejes transversales en los planes de estudio y en el quehacer en general. 
El convertir en una realidad la incorporación de los ejes transversales en el quehacer institucional es un proceso lento, que pasa no solo por la clarificación de creencias, el replanteamiento de las actitudes y del comportamiento, venciendo barreras que permitan pasar del dicho al hecho, sino también por el cambio de la cultura organizacional.

Es de esperarse que en una segunda etapa, así como se cuenta con una Política Ambiental, la UNA defina los compromisos y estrategias para los ejes de equidad, género, diversidad cultural.

\section{El proceso de definición de los ejes transversales institucionales}

Considerando lo establecido en la Política Ambiental, la definición de ambiente y la definición de los valores y ejes transversales realizada en el III Congreso Universitario, la dirección de Docencia de la Universidad Nacional generó un proceso de discusión y análisis sobre los ejes transversales institucionales, en primera instancia en un grupo focal y luego con la Comisión de Desarrollo Curricular de la Universidad integrada por los vicedecanos y vicedecanas, que permitió identificar traslapes, agrupar los ejes y caracterizarlos de la siguiente manera:

"Los ejes transversales forman parte de la filosofia y cultura institucional e incluyen conocimientos, actitudes, comportamientos, principios, valores y concepciones que están acordes con la misión, visión, valores de la universidad. Dinamizan la vida universitaria en todos sus ámbitos e inciden en la formación integral de los estudiantes y en el resto de la comunidad universitaria, puesto que se incorporan en la cotidianidad como vivencias, en las disciplinas, los contenidos $y$ en todo su quehacer. Se definieron como ejes transversales: género, cultura ambiental, equidad y diversidad cultural, todos ellos se articulan alrededor del eje Desarrollo humano sostenible" (Dirección de Docencia, 2003).

En la siguiente figura, se representan los ejes transversales de la UNA. 
Figura 1. Representación de los ejes transversales institucionales y sus relaciones en el quehacer de la Universidad Nacional

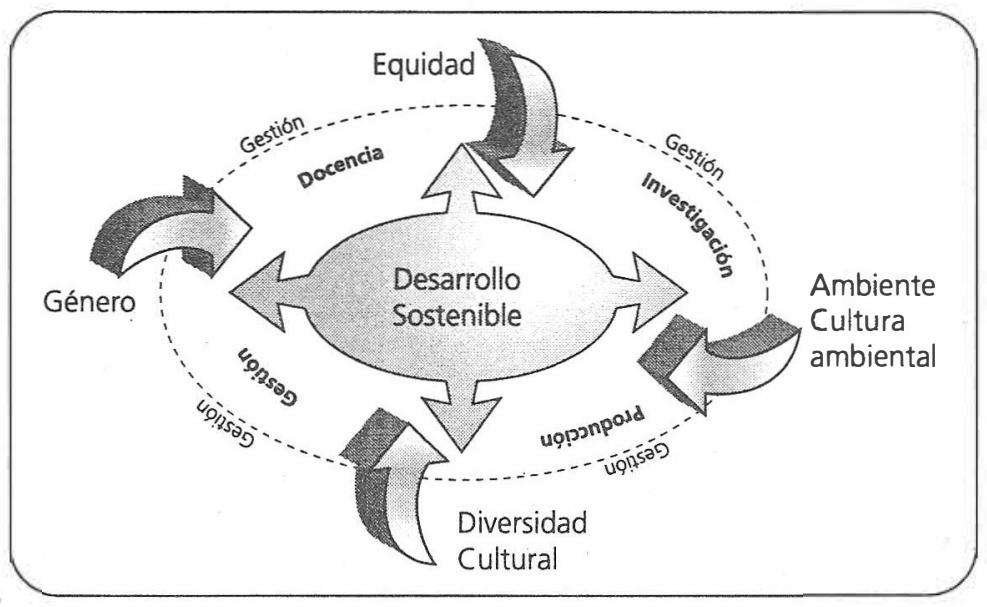

Fuente: Dirección de Docencia-UNA (2003).

Asimismo, la Dirección de Docencia elaboró una estrategia que permitiera la inclusión de los ejes en los planes de estudio. Para tal efecto, se llevaron a cabo talleres con las Facultades y Centros para discutir la propuesta de definición de los ejes transversales institucionales elaborada en la Comisión Institucional de Desarrollo Curricular, y la inclusión de estos en los planes de estudio, aprovechando el proceso de rediseño curricular de todas las carreras que realizaría la UNA para la reorganización de los ciclos lectivos. También se organizaron Foros Universitarios para cảda uno de los ejes transversales definidos, con especialistas en la temática, que permitieron la sensibilización y actualización de las autoridades y responsables de la inclusión de los ejes en los planes de estudio, así como de los académicos en general.

Posteriormente, se desarrolló un proyecto de investigación a cargo de un grupo de académicos de la Dirección de Docencia, con el objetivo de investigar estrategias, metodologías y formas de acompañamiento necesarias para que el personal académico de la UNA lograra insertar los ejes institucionales en los planes de estudio.

Las metas establecidas en el proyecto guiaron las actividades y acciones realizadas. La incorporación de los ejes en los cursos se llevó a cabo con 
investigaciones-acción y proyectos piloto. Estamos ahora en la sistematización y divulgación de los resultados obtenidos ${ }^{2}$.

Dado que Charpentier (1995) concluyó en su investigación que se debía prestar especial atención al autocontrol -que se refiere a la facilidad o dificultad que una persona cree que tiene para realizar una acción, en este caso la incorporación de los ejes transversales en los cursos-, se seleccionaron las barreras que más impedían la inclusión de los ejes, para atenderlas en el acompañamiento. Además, se decidió trabajar con el modelo de "Acción Ambiental Positiva" de Emmons (1997), el cual también fue utilizado en el estudio de Mata et al. (2003). Este modelo utiliza cuatro variables como predictoras de la acción que son: 1) actitudes y sensibilización, 2) habilidades, 3) conocimientos y 4) apropiación o pertenencia. Se prestó especial atención a las variables habilidades y apropiación o pertenencia.

El siguiente esquema resume el proceso de definición de los ejes transversales en la UNA.

Figura 2. Representación esquemática del proceso para definir los ejes transversales en la UNA

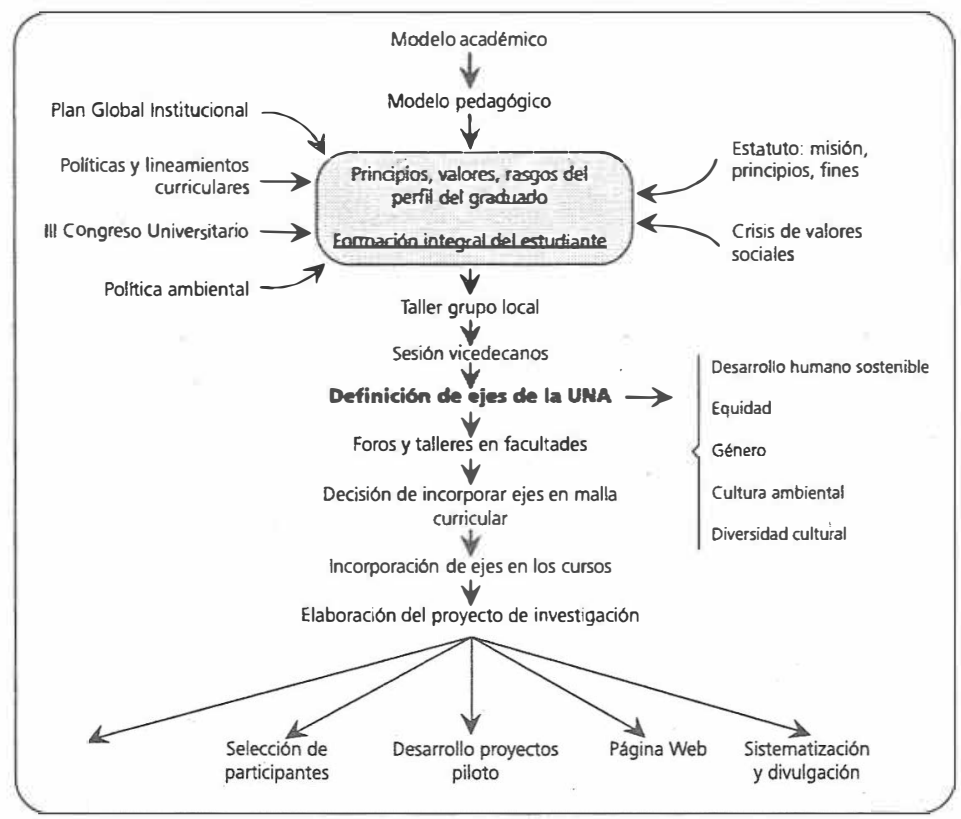

2 El proceso detallado seguido en la Universidad Nacional para la incorporación de los ejes transversales institucionales, a saber: 1) Ambiente y Cultura ambiental, 2) Género, 3) Equidad, 4) Diversidad Cultural y 5) Desarrollo Sostenible, como parte del rediseño curricular, está descrito en Charpentier y Jiménez (2006). 


\section{El proceso de acompañamiento}

El equipo conductor del proceso institucional de incorporación de los ejes transversales buscó un modelo que permitiera tener las variables bien definidas para el acompañamiento, pues se tiene claro que hay variables que influyen en que una persona se decida a incorporar los cambios que se promueven en la institución. Uno de los modelos es el de Fishbein y Ajzen (1975), quienes plantearon que la intención de una persona de realizar una conducta estaba influida por las actitudes y la gente que es importante para él o ella. Luego, el modelo fue modificado por Ajzen (citado por Charpentier, 1995), quien incluyó una tercera variable, el autocontrol.

Esos modelos establecen que las variables están influidas por las creencias que tienen las personas, las cuales son producto de los conocimientos que poseen. Por lo tanto, cuando los conocimientos son incorrectos forman creencias incorrectas. Esos modelos han sido utilizados para predecir intenciones muy variadas, desde la participación en la recreación (Ajzen y Driver, 1991), hasta la incorporación de la dimensión ambiental en las universidades (Charpentier, 1995).

En un modelo más reciente, se incluyen cuatro variables para predecir la acción ambiental positiva: empoderamiento, conocimientos, habilidades y actitudes (Emmons, 1997). Este modelo ayuda a ubicar mejor dónde están las barreras más fuertes del personal docente de la UNA, sin tener que investigar sobre sus creencias y se identificaron a partir de las solicitudes de actualización y colaboración que hicieron las personas que participaron voluntariamente en esta experiencia piloto. 
Figura 3. Principales elementos del acompañamiento que se brindó a docentes de la Universidad Nacional para incluir los ejes transversales

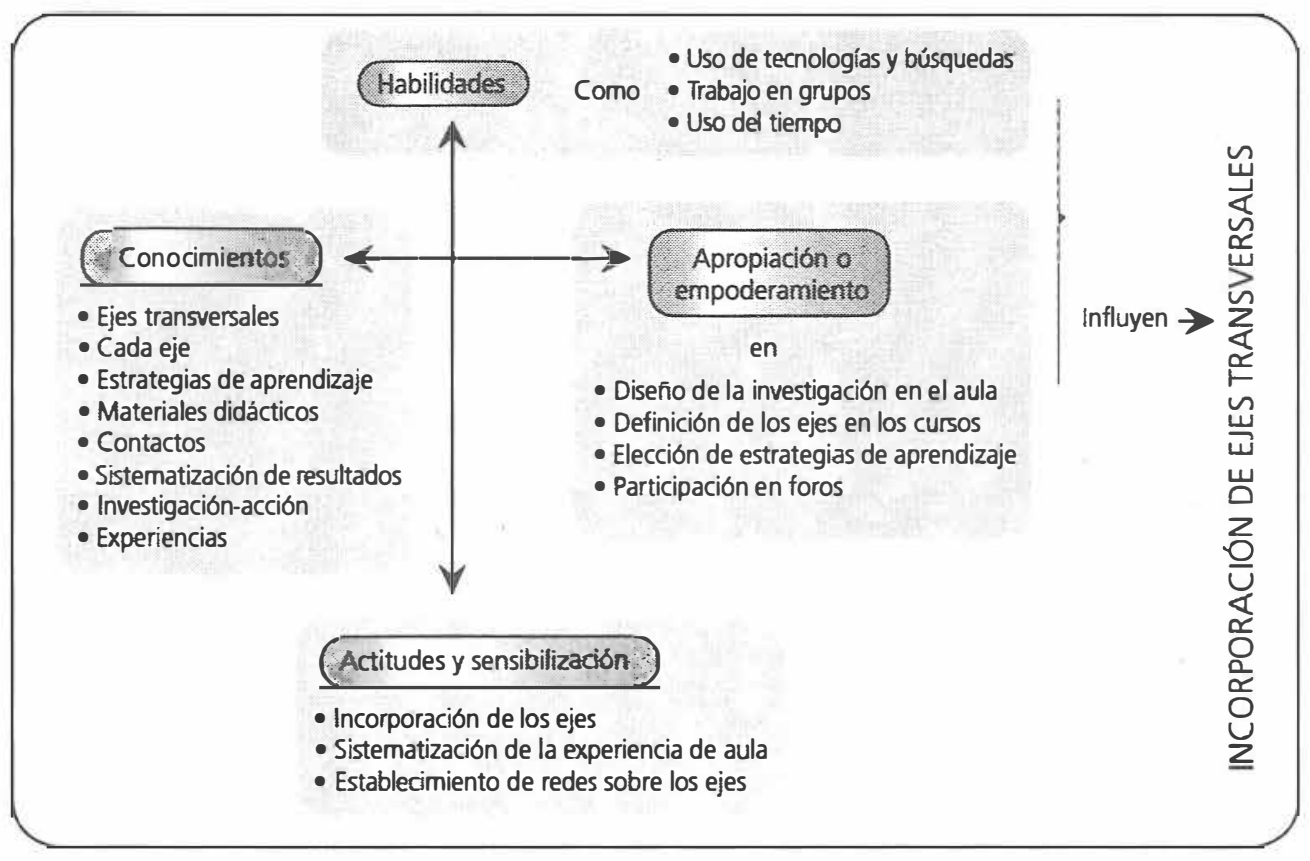

Fuente: Elaboración propia a partir del "Modelo de Acción Ambiental Positiva” de Emmons (1997).

Como se puede observar, las solicitudes planteadas durante el acompañamiento fueron variadas, aunque una mayor cantidad se refirió a conocimientos y al empoderamiento para la realización de los proyectos de investigación-acción que se realizaron en el aula. Las necesidades más grandes se encontraron en la definición de los ejes transversales y la forma de incorporarlos en el aula, las estrategias de enseñanza más adecuadas para incluir el eje o los ejes en el trabajo de aula y las experiencias realizadas por otros profesores y otras profesoras que pudieran servir para ilustrar las vivencias que se podrían dar en sus clases.

Las experiencias individuales y grupales fueron tan variadas que se van a analizar los casos que más ayudaron a divulgar los resultados de este acompañamiento para la incorporación de los ejes transversales en la Universidad Nacional. 
Así, a partir de la decisión que se tomó en el 2003 de incorporar los ejes transversales institucionales en el quehacer de la UNA, podemos decir que en las mallas curriculares de todos los planes de estudio se señala la inclusión de los ejes transversales. Sin embargo, no en todas las carreras se ha logrado incluir los ejes en los cursos. Lo anterior debido, en parte, a que un gran porcentaje de los docentes que participaron en los foros de sensibilización sobre los ejes transversales se habían pensionado, por lo que muchas personas los desconocían y, sobre todo, no sabían de la obligatoriedad de acatar este acuerdo. Se suma a esto el hecho de que faltó convencimiento en las comisiones curriculares y en las instancias de apoyo para lograr operacionalizar esta decisión institucional.

Esta situación se mantiene y sólo se superará, si se retoma el proceso de sensibilización y actualización de la comunidad universitaria, empoderando y brindando seguimiento a las comisiones curriculares, y finalmente cuando cada docente participe en la definición de cuál o cuáles ejes pueden ser incorporados en cada uno de los cursos que imparte.

\section{Niveles de acompañamiento}

\section{Para docentes}

Al inicio del proceso, todas las personas que generaron los proyectos de investigación-acción sobre la incorporación de los ejes transversales institucionales en los cursos lo hicieron voluntariamente. En algunos casos, por recomendación de las autoridades de los vicedecanatos, otras se inscribieron en los talleres que se realizaron en Unidades Académicas, Facultades, Centros o Sedes Regionales. Después de que cada participante seleccionó el curso en el que quería participar, se procedió a elegir el o los ejes y la estrategia o las estrategias de enseñanza-aprendizaje por utilizar. Algunas veces ya la habían utilizado y, en otros casos, fue necesario tener una breve discusión sobre las estrategias.

Una vez que se tuvo el eje o los ejes y la estrategia de aprendizaje, se definió el plan de acompañamiento más adecuado para cada persona. En todos los casos, se solicitó material impreso y, por lo tanto, se diseñó un paquete que incluyó:

a. descripción de la estrategia de enseñanza-aprendizaje y modo de empleo, 
b. lecturas sobre el eje transversal,

c. experiencias anteriores, si había.

En otros casos, el acompañamiento incluyó visitas al aula para observar al estudiantado, envío de listas de revistas virtuales en educación, traslado de artículos por correo electrónico, aclaración de consultas por teléfono o correo electrónico. En los últimos talleres que se realizaron en unidades académicas, se entregó al director o directora un paquete para el trabajo en grupos, que contenía no sólo los documentos anteriores, sino también los artículos sobre los diferentes ejes.

Es importante indicar que entre el grupo de docentes que participó, había personas sin experiencia en la incorporación de ejes transversales, pero dispuestas a innovar, descubrir y aprender, otras personas sí contaban con experiencia y decidieron trabajar con ejes nuevos para continuar formándose ${ }^{3}$.

Como se muestra en el cuadro 1 , los ejes se han incorporado en una variedad de cursos y de ellos, el mayor número de experiencias se han dado con el eje del ambiente y cultura ambiental. Por esa razón, es necesario que la malla curricular de cada plan de estudios, indique el eje o los ejes a incluir en cada curso. Este paso se ha dado en muy pocas unidades académicas.

Cuadro 1. Algunos cursos en los que se han incluido los ejes transversales de la Universidad Nacional

\begin{tabular}{|l|l|l|l|l|}
\hline $\begin{array}{l}\text { Desarrollo } \\
\text { sostenible }\end{array}$ & Género & $\begin{array}{l}\text { Diversidad } \\
\text { cultural }\end{array}$ & $\begin{array}{l}\text { Ambiente y } \\
\text { cultura ambiental }\end{array}$ & Equidad \\
\hline & $\begin{array}{l}\text { Geologia (Topo- } \\
\text { grafia) }\end{array}$ & $\begin{array}{l}\text { Metodologia de la } \\
\text { acción comunitaria } \\
\text { (Planificación y } \\
\text { Promoción Social) }\end{array}$ & \\
\hline & $\begin{array}{l}\text { Metodologia de la } \\
\text { acción comunitaria } \\
\text { (Planificación y } \\
\text { Promoción Social) }\end{array}$ & & $\begin{array}{l}\text { Aprendizaje motor } \\
\text { yundamentos } \\
\text { psicosociológicos } \\
\text { (Ciencias del } \\
\text { Deporte) }\end{array}$ & \\
\hline & $\begin{array}{l}\text { Aprendizaje motor } \\
\text { y fundamentos } \\
\text { psicosociológicos } \\
\text { (Ciencias del } \\
\text { Deporte) }\end{array}$ & $\begin{array}{l}\text { Ciencia y Tecnolo- } \\
\text { gia (Centro de Es- } \\
\text { tudios Generales) }\end{array}$ & \\
\hline & & & \\
\hline
\end{tabular}

3 Los proyectos realizados pueden consultarse en el sitio web de la Dirección de Docencia. 


\begin{tabular}{|l|l|l|l|l|}
\hline $\begin{array}{l}\text { Embriologia (Me- } \\
\text { dicina Veterinaria) }\end{array}$ & & $\begin{array}{l}\text { Embriología (Me- } \\
\text { dicina Veterinaria) }\end{array}$ & \\
\hline & $\begin{array}{l}\text { Arte y cultura } \\
\text { populares (Centro } \\
\text { de Estudios Gene- } \\
\text { rales) }\end{array}$ & $\begin{array}{l}\text { Arte y cultura } \\
\text { populares (Centro } \\
\text { de Estudios Gene- } \\
\text { rales) }\end{array}$ & & \\
\hline
\end{tabular}

Nota: entre paréntesis se indica la unidad académica en la que se imparte el curso.

La incorporación de ejes se ha desarrollado de una forma muy creativa, tal y como se puede observar en el cuadro 2. En algunos casos, la propuesta es individual; sin embargo, en la mayoría, es el resultado de trabajo en grupos de docentes que imparten diferentes cursos y en diferentes unidades académicas.

\section{Cuadro 2.}

\begin{tabular}{|c|c|c|c|c|}
\hline $\begin{array}{l}\text { Desarrollo } \\
\text { sostenible }\end{array}$ & Género & $\begin{array}{l}\text { Diversidad } \\
\text { cultural }\end{array}$ & $\begin{array}{l}\text { Ambiente } y \\
\text { cultura ambiental }\end{array}$ & Equidad \\
\hline $\begin{array}{l}\text { Incluir en el } \\
\text { infonne de visita } \\
\text { a los mataderos el } \\
\text { análisis de los va- } \\
\text { lores de la empresa } \\
\text { y la calidad de vida } \\
\text { de los animales } \\
\text { que iban a ser } \\
\text { sacrificados }\end{array}$ & $\begin{array}{l}\text { Análisis de lec- } \\
\text { turas en el curso } \\
\text { donde se detenni- } \\
\text { nó si se utilizaba el } \\
\text { lenguaje inclusivo } \\
\text { y la visión del gé- } \\
\text { nero femenino y } \\
\text { masculino }\end{array}$ & $\begin{array}{l}\text { Reconocimiento } \\
\text { de la diversidad } \\
\text { cultural presente } \\
\text { en el aula }\end{array}$ & $\begin{array}{l}\text { Elaboración de } \\
\text { un portafolio } \\
\text { en el curso que } \\
\text { permita visualizar } \\
\text { los cambios de } \\
\text { cada estudiante } \\
\text { hacia el ambiente } \\
\text { y sobre su cultura } \\
\text { ambiental }\end{array}$ & $\begin{array}{l}\text { Elaboración de } \\
\text { una ficha sobre } \\
\text { cada estudiante, } \\
\text { de manera que se } \\
\text { tenga información } \\
\text { relevante de sus } \\
\text { características } \\
\text { y se le trate con } \\
\text { equidad }\end{array}$ \\
\hline $\begin{array}{l}\text { Completar el quiz } \\
\text { de la Huella eco- } \\
\text { lógica y discutir } \\
\text { acciones para } \\
\text { disminuirla }\end{array}$ & $\begin{array}{l}\text { Utilización del } \\
\text { lenguaje inclusivo } \\
\text { en el aula por } \\
\text { parte de docentes y } \\
\text { estudiantes }\end{array}$ & $\begin{array}{l}\text { Investigación en el } \\
\text { aula, incluyendo } \\
\text { la investigación- } \\
\text { acción }\end{array}$ & $\begin{array}{l}\text { Investigación en el } \\
\text { aula, incluyendo } \\
\text { la investigación- } \\
\text { acción }\end{array}$ & $\begin{array}{l}\text { Efectuar un diag- } \\
\text { nóstico de los esti- } \\
\text { los de aprendizaje } \\
\text { del estudiantado }\end{array}$ \\
\hline $\begin{array}{l}\text { Discusiones en el } \\
\text { aula sobre desarro- } \\
\text { llo sostenible }\end{array}$ & & $\begin{array}{l}\text { Incorporación de } \\
\text { temas en el curso }\end{array}$ & $\begin{array}{l}\text { Desarrollo de pro- } \\
\text { yectos ambientales } \\
\text { durante el curso }\end{array}$ & $\begin{array}{l}\text { Vivencia de la } \\
\text { equidad en el aula }\end{array}$ \\
\hline $\begin{array}{l}\text { Separación de de- } \\
\text { sechos en el aula }\end{array}$ & & $\begin{array}{l}\text { Realización de ac- } \\
\text { tividades culturales } \\
\text { en la zona }\end{array}$ & & $\begin{array}{l}\text { Discusión sobre } \\
\text { tareas y asignacio- } \\
\text { nes en el curso }\end{array}$ \\
\hline $\begin{array}{l}\text { Lecturas sobre el } \\
\text { tema }\end{array}$ & & $\begin{array}{l}\text { Vivencia en el aula } \\
\text { del respeto a la } \\
\text { diversidad cultural } \\
\text { del estudiantado. }\end{array}$ & & $\begin{array}{l}\text { Vivencias en el } \\
\text { aula del respeto } \\
\text { a la predilección } \\
\text { sexual, de credo y } \\
\text { afiliación política }\end{array}$ \\
\hline $\begin{array}{l}\text { Investigaciones } \\
\text { durante el curso }\end{array}$ & & & & $\begin{array}{l}\text { Investigación en el } \\
\text { curso }\end{array}$ \\
\hline
\end{tabular}




\begin{tabular}{|l|l|l|l|l|}
\hline $\begin{array}{l}\text { Propuesta de } \\
\text { mercadeo de } \\
\text { productos verdes } \\
\text { identificados por el } \\
\text { estudiantado }\end{array}$ & & & & \\
\hline $\begin{array}{l}\text { Definición de con- } \\
\text { ductas aceptables } \\
\text { e inaceptables para } \\
\text { las personas del } \\
\text { curso }\end{array}$ & & & & \\
\hline
\end{tabular}

Los resultados obtenidos muestran que el personal docente de la Universidad Nacional puede proponer diversas formas de incluir los ejes transversales en sus cursos; esto les permite superar la barrera: tengo la motivación, pero no sé cómo hacerlo y hacerlo demanda más tiempo que no tengo en el curso. No obstante, si no se da el seguimiento necesario, el esfuerzo se mantiene como una propuesta y no todo el profesorado la pone en práctica.

\section{Para una Unidad Académica}

La primera parte de la incorporación de ejes transversales era individual, pero en varios casos las personas que participaron convencieron a las autoridades de su unidad académica de participar en la experiencia y, por lo tanto, se llegó a realizar al menos un taller en cada unidad académica. Sólo en el caso de la Escuela de Topografía, Catastro y Geodesia se realizaron dos talleres y se dio seguimiento al profesorado de la Unidad Académica. Esta Escuela permite comprobar la premisa con la que se inició este proceso en la Universidad Nacional: todos los ejes transversales institucionales se pueden incluir en todas las carreras.

En todos los casos, se inició con un taller de inducción, que incluía una breve descripción del proyecto de incorporación de ejes transversales y se realizaba un ejercicio, que concluía con el trabajo en grupos de las personas que habían seleccionado el mismo eje transversal en su curso.

Con el grupo de docentes de cada unidad académica, se estableció una red a la que se les envían documentos y avisos importantes. Las participaciones en las unidades académicas han dado mayores frutos, porque permiten poner a trabajar en ejes a docentes que laboran en un mismo plan de estudio. 


\section{Para una Sede Regional}

La Universidad Nacional cuenta con dos sedes regionales y varios campus en cada una. El trabajo en las sedes fue muy motivante, porque la participación de docentes en proyectos de investigación-acción fue mayor que en las unidades académicas de la sede central. También constituye el número de docentes más constante en el uso de correo electrónico. 


\section{Referencias}

Ajzen, I. y Driver, B. L. (1991). "Prediction of leissure participation from behavioral, normative and control beliefs: An application of the Theory of Planned Behavior". Leissure Sciences (13), 185-204.

Benayas, J. y Alba, D. (s.f.) El reto de la ambientalización universitaria. Recuperado el 13 de enero del 2006, de http//www.usc.es/ calidad/doc/e-boletin\%20maio.

Charpentier, C. y Jiménez, L. (2006). "La inserción de ejes transversales en la Universidad Nacional es un proceso flexible y participativo". Revista Contexto Normalista 2: saldrá en los próximos meses.

Charpentier, C., Hemández, L., Zúñiga, C., Brenes, O. E., Mata, A., Carrillo, M. A., y Zúñiga, M. E. (2002). Comisión Interuniversitaria de Educación Ambiental. "Indicadores que hay para medir la incorporación de la dimensión ambiental en los currícula de las universidades estatales de Costa Rica". Revista de Ciencias Ambientales (22), 40-43.

Charpentier, C. y Ham, S. (1997). "Una nueva perspectiva para clasificar barreras para la incorporación de la dimensión ambiental en la educación superior en Costa Rica". En: Amáez, E. y Rojas, S. Experiencias para la incorporación de la dimensión ambiental en el quehacer universitario. Consejo Nacional de Rectores, Costa Rica (OPES-07/97).

Charpentier, C. (1995). Barriers to environmental education in Costa Rican State Universities: Theory, analysis and recommendations for intervention programs. Published doctoral dissertation, University of Idaho, Moscow.

Consejo Universitario. (2003a). "Políticas y Lineamientos Curriculares". SCU-2792003. Gaceta 3.

Consejo Universitario. (2003b). "Políticas y Lineamientos Curriculares". SCU-8202003. Gaceta 3.

Díaz-Barriga, F. y Hemández, G. (1998). Estrategias docentes para un aprendizaje significativo, una interpretación constructivista. México: MCGRAW-HILL.

Dirección de Docencia. (2003). Programa de Evaluación y Gestión de la Calidad Académica, Comisión de Vicedecanos y Vicedecanas, Dirección de Docencia, Universidad Nacional. Incorporación de ejes transversales en los planes de estudio. (http:// www.una.ac.cr/peva/).

Emmons, K. (1997). "Perspectives on environmental acting: reflection and revision through practical experience". Journal of Environmental Education 29 (1), 34-44.

Ham, S. y Sewing, D. R. (1988). "Barriers to Environmental Education". Journal of Environmental Education 19 (2), 17-24. 
Mata, A., Zúñiga, C., Brenes, O., Carrillo, M. A., Charpentier, C., Hernández, L. y Zúñiga, M. E. (2003). Informe final Dimensión ambiental: estrategias innovadoras para la formación docente. Coordinación Educativa Cultural Centroamericana (CECC). Costa Rica: IMPRESORA OBANDO.

Mata, A., Zúñiga, C., Brenes, O., Carrillo, M. A., Charpentier, C., Hernández, L. y Zúñiga, M. E. (2002). "Dimensión ambiental: estrategias innovadoras para la formación docente". Coordinación Educativa Cultural Centroamericana (CECC), Colección Pedagógica Formación Inicial de Docentes Centroamericanos en Educación Primaria o Básica. Volumen 27.

Política Ambiental Universidad Nacional, Acta $\mathrm{N}^{\circ} 2472$, Gaceta $\mathrm{N}^{\circ} 7,30$ junio del 2003.

Romero, R. (1991). "La dimensión ambiental en la formación de profesionales universitarios". Revista de Ciencias Ambientales 7. pp. 112-115.

Universidad Nacional (2004). Plan Global Institucional 2004-2011. UNIVERSIDAD NACIONAL. 